\title{
Necessary and Supportive Conditions for Transfer of Knowledge: A Conceptual Framework
}

\author{
SHABANA GUL \\ Assistant Professor, Institute of Management Sciences, Peshawar \\ Email:shabana.gul@imsciences.edu.pk \\ WASEEF JAMAL \\ Associate Professor, Institute of Management Sciences, Peshawar \\ Email: waseef.jamal@imsciences.edu.pk
}

\begin{abstract}
This paper highlights the conditions (within the organizational environment) that play a vital role in pursuing the sender to share knowledge and the receiver motivated enough to reproduce or apply the received knowledge. Though these conditions are discussed in knowledge transfer literature, yet a comprehensive framework based on all the elements of transfer of knowledge is not available. This study has taken the basic two-person communication model into account and has defined two sets of conditions that are essential for the transfer of knowledge. The first tier of the framework is the communication nucleus which defines the elements of transfer of knowledge aligned with the two-person communication model whereas, the second tier of the framework spells out the conditionality for a successful transfer of knowledge. Two sets of conditions; one based on content factors labeled as necessary conditions and the other based on contextual factors labeled as supportive conditions are comprehensively explained. The framework claims that content factors are necessary for the transfer of knowledge and their absence will cease the transfer process whereas supportive condition accelerates the transfer process, their absence though may not cease the transfer process. The conceptual framework can be used as a set of policy guidelines for the knowledge management strategy formation and application within organizations along with creating the conducive environment required for creating and nurturing opportunities for transfer of knowledge.
\end{abstract}

Keywords: Knowledge Transfer, Conditions for Transfer of Knowledge, Communication Nucleus.

\section{Introduction}

Knowledge management has emerged as a discipline that assists organizations in creating competitive advantage. Numerable approaches are implemented across organizations to take full advantage of knowledge management strategies within and among organizations (Bolisani, \& Bratianu, 2018). Though, the knowledge management literature includes a list of approaches and strategies, yet, very few are specifically designed for the transfer of knowledge (Rhodes et al., 2008; Webb, 2017).Transfer of knowledge (ToK) is one of the component of knowledge management and is about the actual movement of knowledge from knowledge holder (individual, group, and organization) to knowledge receiver (Narteh, 2008; Krylova, Vera, \& Crossan, 2016). Since ToK is the communication of knowledge between the sender and receiver of knowledge, an understanding of the basic communication model (Krone, Jablin \& Putnam, 1987) elaborating encoder, message, medium, decoder, and feedback is important. Communication or message sharing is the crux of the two person communication model whereas the entire process of ToK is also based on transferring the knowledge from sender/holder of the knowledge to that of the receiver of 
knowledge therefore the elements of both the constructs are defined in a similar manner with minor distinctions in jargons only. The encoder in the communication model is the knowledge sender or knowledge holder in the ToK process, knowledge to be transferred is the message, relationship between knowledge holder and receiver is the medium or link whereas the receiver of knowledge is the decoder in the communication model and the feedback that completes the two-person communication is termed as the new knowledge creation as a result of successful knowledge transfer. Table-1 summarises it as follows:

Table-1: Two-Person Communication Model and Elements of TOK

\begin{tabular}{|l|l|}
\hline $\begin{array}{l}\text { Two-Person Communication Model } \\
\text { (Krone, Jablin \& Putnam, 1987) }\end{array}$ & Elements of Transfer of Knowledge \\
\hline Encoder & Knowledge Holder/ Sender (individual, group, or org.) \\
\hline Message & Knowledge \\
\hline Channel/Medium & Link (Relationship) \\
\hline Decoder & Knowledge Receiver (individual, group, or org.) \\
\hline Feedback & $\begin{array}{l}\text { New knowledge creation (output e.g. the number of patents } \\
\text { acquired, no. of new processes developed etc. }\end{array}$ \\
\hline
\end{tabular}

A number of studies have used frameworks that incorporate the basic communication model and explain the characteristics of the elements of transfer of knowledge, e.g. Liyanage et al. (2009) focused on the characteristics of the sender (knowledge holder) and the receiver of knowledge. The study highlighted the sender's willingness, the relevancy of knowledge, and the receiver's absorptive capacity as important factors for a successful transfer of knowledge. The focus of Liyanage et al. (2009) study is the transmission process only. Narteh (2008), however, focused on transferor (sender) and transferee (receiver) of knowledge and asserted that transferor and transferee face two sets of factors. Since the characterizes of transferor and transferee are unique therefore one set is labeled as unique factors. Unique factors include the nature of knowledge, the teaching of knowledge and method of knowledge adopted for transfer for the transferor and learning intent, absorptive capacity, and reward systems for the transferee. The second set of factors are labeled as relationship factors based on the interaction between transferor and transferee. Relationship factors include inter- culture fit, trust, partner selection, method of knowledge transfer, interaction, and business readiness. The model though discusses the conversion, routing, dissemination, and application of knowledge but does not discuss the characteristics of the knowledge to be transferred in the process.

In another study by Bou-Llusar and Segarra-Cipre's (2006) characteristics of knowledge in terms of types of knowledge are comprehensively discussed. Whereas, the remaining elements of the transfer of knowledge process are ignored as the focus of the framework remained to be the nature of knowledge i.-e. tacit or explicit, the complexity of knowledge, the specificity of knowledge, and the systemic nature of knowledge. The study does highlight the importance of understanding the characteristics of the source and recipient units of knowledge along with organizational context yet the focus of the model stayed to be the characteristic of knowledge only. Minbaeva and Michailova (2004) on the other hand focused on the sender of the knowledge and highlighted the importance of the sender's willingness to share knowledge and the ability to share knowledge as crucial for a successful transfer of knowledge, ignoring the remaining elements of ToK process. Bhagat et al. (2002), however comprehensively defined the knowledge element of the ToK process and thoroughly discussed complexity, tacitness, independence, and systemic nature of knowledge. The characteristics of the sender and receiver were also discussed but the discussion was limited to the cognitive styles only. In Gupta and Govindarajan's (2000) study the discussion on the elements of ToK was limited to the value of knowledge and motivational disposition of the knowledge holder and receiver and a brief about the link in terms of a channel between the sender and receiver of knowledge. 
The aforementioned studies though provided frameworks and models for ToK yet they did not take into account the elements of the ToK process in its entirety. The two-person communication model provides a good base for comparing the need for certain elements that are essential for taking the message across thus sender, receiver, knowledge, the link between the sender and receiver along with new knowledge creation are the minimum requirement of any model that attempts to explain the ToK process. Similarly, ToK doesn't take place in isolation, it requires certain conditions that either work as pre-requisites for initiating and completing the transfer process or they work as supportive factors that accelerate the already initiated ToK process. These conditions are subject to the elements of the ToK process or in other words, these conditions arise because of the characteristics of the elements of the ToK process. The following table summarises the aforementioned discussion on TOK frameworks and lack of attention to the use of elements of the communication model.

Table-2. Comparison of Existing Models with Elements of ToK Process

\begin{tabular}{|l|c|c|c|c|c|}
\hline \multirow{2}{*}{ ToK Models/ Framework } & \multicolumn{5}{|c|}{ Characteristics } \\
\cline { 2 - 6 } & $\begin{array}{c}\text { Knowledge } \\
\text { Holder }\end{array}$ & Knowledge & Relationship & $\begin{array}{c}\text { Knowledge } \\
\text { Receiver }\end{array}$ & Feedback \\
\hline Liyanage et all, (2009) & $\checkmark$ & $\checkmark$ & ND* & $\checkmark$ & ND \\
\hline Narteh (2008) & $\checkmark$ & ND & $\checkmark$ & $\checkmark$ & ND \\
\hline $\begin{array}{l}\text { Bou-Llusar \& Segarra-Cipre } \\
\text { (2006) }\end{array}$ & $\checkmark$ & $\checkmark$ & ND & $\checkmark$ & ND \\
\hline Minbaeva \&Michailova (2004) & $\checkmark$ & ND & ND & ND & ND \\
\hline Goh (2002) & $\checkmark$ & $\checkmark$ & ND & $\checkmark$ & ND \\
\hline Bhagat et al., (2002) & $\checkmark$ & $\checkmark$ & ND & $\checkmark$ & ND \\
\hline Gupta \& Govindarajan (2000) & $\checkmark$ & ND & $\checkmark$ & $\checkmark$ & ND \\
\hline
\end{tabular}

*Not Discussed

In the backdrop of the identified gap in the literature, this study set the following objectives.

1. Incorporate the two-person communication model in a conceptual framework for the transfer of knowledge among individuals/groups/organizations.

2. Identify conditions required for a smooth transfer of knowledge.

3. Develop a conceptual framework that will distinguish among the content and contextual factors for the transfer of knowledge.

\section{The Framework}

The framework is divided into two sections: the communication nucleus and the transfer of knowledge conditionality.

\section{a. Section-I: The communication nucleus}

The communication nucleus is based on a two-person communication model and identifies five elements of the ToK process as mentioned in table-1. The elements are diagrammatically shown as follows: 
Figure No: 1

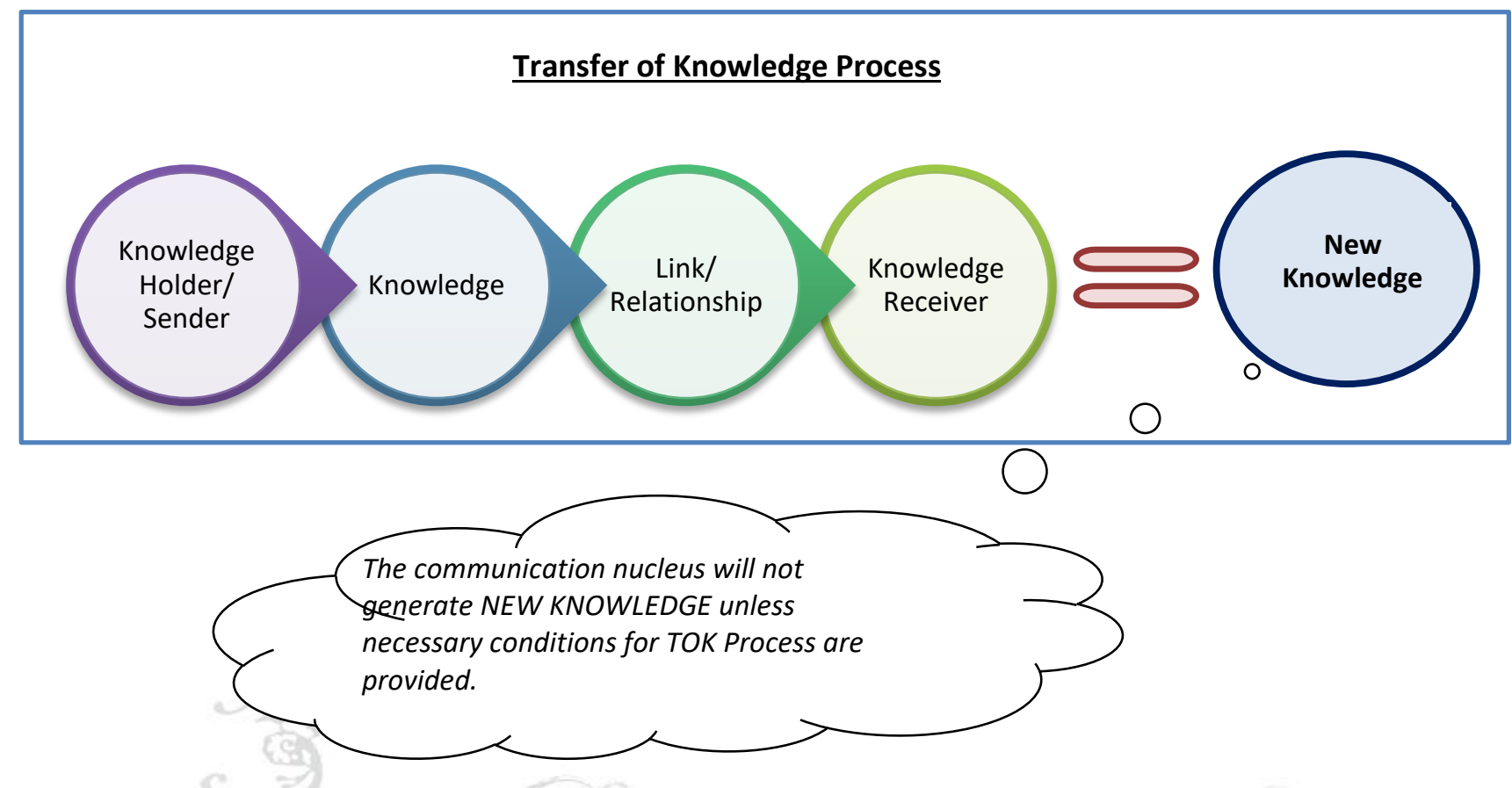

Identification and discussion on the elements of the ToK process are essential for creating a conducive environment or a knowledge-based culture within an organization. The knowledge holder or sender is the keeper of knowledge, the one who initiates the transfer process, the sender sends the knowledge, exactly the way in which a sender in two-person communication ode sends a message. In the ToK process, the message is the knowledge to be sent across. The knowledge sender uses a link for sending the knowledge to the knowledge receiver and the receiver upon receiving uses the received knowledge for further knowledge creation. Now at each stage from knowledge sending initiative to receiving and knowledge creation a number of contextual and content conditions are at play. These conditions are basically generated as an output of the characteristics of the elements of ToK.

\section{b. Section II: Transfer Conditionality:}

In this section of the framework transfer conditionality's are identified and defined. Successful transfer of knowledge from a sender to receiver depends on the embedded characteristics of elements of TOK along with supportive environmental factors. The embedded characteristics of each of the elements of TOK are vital for the transfer process, therefore they are identified as necessary conditions. The lack of these characteristics in elements of TOK will stop/hinder the transfer process. Whereas contextual factors are the supportive characteristics present in the environment. It is assumed that the presence of these supportive conditions will accelerate the transfer process, however, their absence will not stop/hinder the transfer process unlike the necessary conditions.

\section{i. Necessary conditions:}

The framework defines necessary conditions as prerequisites for initiating the ToK process. These conditions emerge from or are an exhibition of the embedded characteristics of the elements of ToK. Organizations must pay attention to the provision of these conditions. The following section discusses the details of these embedded characteristics of elements of the ToK process. 


\section{a. Necessary Conditions for Sender:}

The knowledge holder/sender must have the ability to send or share knowledge. Minbaeva and Michailova (2004) argued that the decision of sharing knowledge is an individual-level decision and is based on the ability and willingness of the knowledge holder, both being behavioral aspects of the sender. High performance at any level requires ability along with the motivation to perform, the same applies to the ToK process. The knowledge holder may not be able to send the required knowledge if the sender lacks the required competencies of knowledge sharing, inadequate knowledge of the language or language insufficiency, and or the confidence in self and in the value of the knowledge to be shared (Cabrera, 2003). Experience of the knowledge sender also plays an important role as the sender feels confident based on past experiences as individuals easily absorb and share the knowledge that they can connect with their existing knowledge. Thus, in nutshell, the required skill set for sharing along with the willingness to share knowledge is a prerequisite for initiating the transfer process on the part of the knowledge holder (Cohen \& Levinthal, 1990).

\section{b. Necessary Conditions for Knowledge/Material:}

Knowledge ambiguity is about the lack of clarity regarding the sources and components of underlying knowledge. The lack of clarity is intrinsic in nature and is complex as it result of knowledge tacitness, complexity, and specificity (Reed \& DeFilippi, 1990; Law, 2014). This lack of clarity due to tacitness of knowledge is a double-bladed sword, on one hand, it protects knowledge from being imitated on the other hand it forbids the knowledge from being transferred (Coff et al., 2006; Ho \& Wang 2015).

The nature or form of knowledge i.e. tacit or explicit also plays a vital role in the ToK process. Since tacit knowledge is personal and un-codified knowledge, therefore, a formal communication of it is difficult as opposed to explicit knowledge which can easily be transferred via formal channels and in a systematic language (Nonaka, 1994; Ellis \& Roever, 2018; Hadjimichael \& Tsoukas, 2019). Organizational knowledge transfer is heavily dependent on the clarity of knowledge sources and their subsequent transmission, interpretation, and absorption (Hansen, 1999; Kogut \& Zander, 1992; Al-Jabri \& Al-Busaidi, 2018). The value of knowledge for the knowledge holder plays an important role in the ToK process. If the knowledge to be transferred benefits the knowledge sender in personal or career development or in completion of an important task the sender will be extra cautious in transferring such knowledge and the receiver of the knowledge will respond in more or less the same manner.

\section{c. Necessary conditions for link/ relationships:}

The relationship dynamics of the knowledge holder and the receiver is an important aspect of the ToK process e.g. distant relationships may result in difficulty in communication (Goh, 2002). Similarly, the frequency of connections, the intensity of the relationship (formal vs. informal connections), social and task similarities are also significant factors in defining the ToK process. Cohen and Levinthal (1990) considered the interaction between individuals with variation in the knowledge base as a crucial factor for innovation. Tsang (2002) however considered the geographical distance between the individuals that creates hurdles for face-to-face interactions. Social network theorists believe that the strength of a relationships is dependent on the interaction frequency, emotional association, and intimacy. The social ties are generally divided into two types; strong toes and weak ties. Strong toes are linked to frequent interactions whereas weak ties are a result of distant and infrequent interactions (Rowley et al., 2000). Strong ties facilitate the transfer of complex and private knowledge as opposed to weak ties that may help in transferring public knowledge or a non-redundant information (Uzzi \& Lancaster, 2003).

Trust between and among employees is the pre-requisite for initiating organizational knowledge transfer (Lane et al., 2001; Szulanski et al., 2004; Ahmad, Mushtaq \& Umar, 2019). Trust enhances the partner's willingness and enables the partners inputting an effort in understanding the new knowledge from external 
sources (Lane et al., 2001). Trust creates a sense of dependency among partners without the fear of being vulnerable, which results in a strengthened relationship for learning and new experiences (Das \& Teng, 1998; Ho, Ghauri, \& Kafouros, 2019). Trust is also found to reduce inter-partner conflict by strengthening the inter-partner ties (Ring \& Van de Ven, 1994). Organizational culture literature has also recorded trust as an influencing factor in knowledge sharing among peers and team members as a culture where members trust on another provide an opportunity for openly sharing knowledge by reducing the cost of asking for help (Gruenfeld et al., 1996; Ahmad, Mushtaq \& Umar, 2019).

\section{d. Necessary conditions for receiver:}

The concept of absorptive capacity was introduced by Cohen and Levinthal (1990) and since its inception has emerged as an important concept in ToK literature. Absorptive capacity is defined as the ability to recognize, adapt and apply the newly acquired knowledge (Cohen \& Levinthal, 1990) thus, the receiver of knowledge must have the capacity to understand, use and re-use the received knowledge. The important role of absorptive capacity is discussed extensively in literature (read e.g. Lane et al., 2006; Zahra \& George, 2002; Saiz, Miguel, \& del Campo, 2018). However, Lane \& Lubatkin, 1998, were sceptical about the applicability of the concept at organizational level as they consider absorptive capacity as a dyadic construct. Yet, there are studies that prove the facilitative role of absorptive capacity in inter-organizational transfer of knowledge (Lane et al., 2001; Mowery et al., 1996).

Along with absorptive capacity, the cognitive ability of the receiver is also vital for knowledge transfer. Cognitive ability refers to a mental capacity of planning; problem solving; comprehension of complex situations; abstract thinking and quick learning from experiences (Batey \& Hughes, 2017). Thus, the receiver of knowledge must be able to process the received knowledge for problem solving and reapplication. If the receiver of knowledge lacks the cognitive ability of comprehending knowledge for a possible re-use or application, the transferred knowledge will lose its value and in the process new knowledge creation will cease to exist.

\section{ii. Supportive Conditions:}

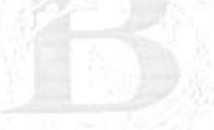

Unlike necessary conditions, supportive conditions are contextual factors, present in the environment. These factors are generally created and or supported by the organization to help create an environment that can nurture the transfer process. Thus, the supportive conditions require support from the organization.

\section{a. Supportive conditions for the sender}

Environmental changes affect the transfer process considerably e.g. if an organization replaces the existing technology with a new one, the transfer process will be directly affected (Sorenson 2003). As the sender will require time to get hands-on experience and learn the new ways of doing the tasks. The same will result in a lack of confidence by the receiver given the lack of experiences of the sender.

Competition among organizational members is natural in any organizational setting but a cut-throat competition may lead to hoarding of knowledge on the part of the knowledge holders. Thus, the organization management needs to help create a healthy competitive environment whereby collaboration and teamwork are the currency of development. Organizational knowledge is not only embedded in members of the organizations but is also entrenched in organizational rules, policies, routines, structure, and culture, thus organizations must work towards a transactive memory assists in knowledge access and retention (Borgatti \& Cross, 2003; Wang, Huang, Davison, \& Yang, 2018). Reduction of physical and psychological distances between people within an organization allows members of the organization to learn from one another. Learning by observing others is an example of such opportunities if created and provided by originations. Individuals can indirectly accumulate knowledge by observing others at work (Nadler et al. 2003; Torabi, Warnell, \& Stone, 2019). Proximity provides members with the opportunity of not only 
locating those with knowledge but also gives them a chance to gain knowledge about where to find or search for more knowledge or information (Borgatti \& Cross 2003). Sharing transfer routines, technologies and tools within organization provides members of the organizations to benefit from knowledge acquired by other members (Epple et al., 1996, Winter \& Szulanski 2001). Informal networks serve the same purpose i.e. making knowledge proximate and help in developing informal ties. Informal ties assist in learning from others without any formal requirements or procedure to fill in for (Martin-Rios, \& Erhardt, 2017; Uzzi \& Lancaster 2003).

The similarity of tasks across contexts is found to be the most fundamental task characteristic that affects the transfer of knowledge. The higher the similarity of the same elements of tasks the greater is the chance for a smooth transfer. The similarity of tasks increases the likelihood of transfer of knowledge is proved at the individual and at the organizational level (Darr \& Kurtzberg, 2000). Grant (1996) argued that prior knowledge or similarity of language enhances the capacity of learning manifold as it helps in interpreting the new experiences.

\section{b. Supportive conditions for knowledge/material:}

The valuation of internal versus external knowledge has been debated since long, Katz \& Allen (1982) tossed the concept of "not-invented-here" (NIH) syndrome as a probable explanation of the inherent bias towards internal knowledge in the face of external knowledge. Managers generally consider internal knowledge superior because of close relationships with the internal organizational members yet, there are theories that claim that favoritism for insiders exists but there are general preferences for external knowledge as well (Menon \& Pfeffer, 2003). Internal knowledge is easily available within the organization and is easy to use as well. However, the ease of access and use can create issues of their own e.g. when knowledge is easily accessible it becomes subject to over scrutiny and the flaws within the available internal knowledge are easy to locate as opposed to external knowledge (Cialdini, 2001). It is difficult to scrutinize external knowledge given the difficulty of access and use, as access issues make the external knowledge scared and unique whereby creating the perception of value (Cialdini, 2001).

Internal and external knowledge differ based on accessibility. Since, members of an organization generally enjoy close proximity therefore frequent communication make internal knowledge easily available and free of cost as well. Similarly, the barriers of legality and technological medium for access are also removed during the process. Managers generally prefer internal knowledge as it is extremely ease to access internal knowledge (Antonelli, \& Colombelli, 2018). The domain in which the knowledge exists i.e. public or private is gaining attention in transfer of knowledge literature (Uzzi \& Lancaster, 2003; Montoya, \& Leazer, 2019). The public domain knowledge is considered to be hard information as opposed to private knowledge which is soft information about an organization, though not equally available. The transfer of public or private knowledge requires different set of ties with the organization (Uzzi \& Lancaster, 2003). Public knowledge can easily be transferred via formal linkages whereas private knowledge transfer requires more close-knit ties. Similarly, if the knowledge to be shared uses the language of the knowledge holder and receiver, the transfer process becomes much easier as opposed to differences in language.

\section{c. Supportive conditions for link/relationship:}

Organizational culture defines the norms, values, core believes and the social customs that are followed by the members of the organizations (Wei \& Miraglia, 2017), thus organizational culture plays an important role in the transfer of knowledge (Davenport et al., 1998).

Chase (1997) affirmed that culture is by large one of the largest obstacle in creation of knowledge-based enterprises. Collaboration between the members of organization is a crucial aspect of an organizational culture from ten transfer of knowledge perspective. Goh (2002) argued that collaboration is one of the prerequisite for successful knowledge transfer. As transfer of knowledge require member to interact, share and 
collaborate for creating new knowledge via transferring the existing knowledge. Collaboration between organizational members is subject to trust among the members and such trust can be observed in knowledge-friendly cultures (DeTienne \& Jackson, 2001; Lee \& Choi, 2003; Seyedyousefi, Fard, \& Tohidi, 2016).

Apart from having a knowledge friendly culture an organization must foster a sense of innovation and openness to new experiences for creating new knowledge. Goh (2002) asserted the organizations must support a culture where the status-co is challenged. Such culture though will require to empower its members and should provide its members the freedom to explore new ways of problem solutions, respecting mistakes if any made in the process of exploring new possibilities thereby reducing the sense of fear of punishment (Stonehouse \& Pemberton, 1999).

\section{d. Supportive conditions for receiver:}

The receiver of knowledge requires access to transactive memory in the system as a supportive condition for accessing and retrieving the stored knowledge. Task similarity between the knowledge holder and receiver supports the ToK process by increasing the likelihood of ToK. The existence of a transactive memory system in the form of a centralized database can support the ToK process for quick access and retrieval of knowledge. Difficulties in accessing knowledge results in delays in completing the ToK process as the sender has to put an additional effort in accessing the knowledge and a subsequent effort of decoding and utilizing the received knowledge.

\section{Putting it together:}

Successful transfer of knowledge requires the identification of elements of TOK and their respective necessary and supportive conditions. The available literature focuses on these elements in pockets. Most of the published discussion is about the characteristics of the sender and receiver of knowledge and its types. Since TOK involves people therefore communication models should be taken into account for understanding the elements of the transfer process. All the elements involved in the transfer process should be studied as per their attributes and required support from the environment. The given conceptual framework takes into account both of these considerations (identification of elements and their required conditionality). In the first stage, elements of TOK are identified using a two-person communication model: sender (the knowledge holder), material (the knowledge to be sent), link (the relationship between sender and receiver), receiver (the recipient of knowledge) and new knowledge creation as feedback. In the second stage, the framework spells the conditions required for the transfer process.

The framework assumes that each of the elements: sender, knowledge, link, and receiver must satisfy the mentioned necessary conditions for TOK initiation. For example, if the sender can't transfer knowledge (one of the necessary conditions for the sender) but the rest of the elements meet the necessary conditions, even then transfer of knowledge cannot be initiated. Similarly, a lack of trust in the sender-receiver relationship will hinder the process, even if all the necessary conditions of the rest of TOK's elements are satisfied. Thus, all the elements of TOK must meet their respective necessary conditions for the activation of the communication nucleus. Along with the necessary conditions, the presence of supportive conditions will accelerate the transfer process. Thus, TOK will become a routine activity in an organization. In other words, necessary conditions are about the capacity and behaviours of people (involved in the transfer process) and their relations whereas supportive conditions are about the overall organization's capacity and support mechanism. Thus, members of the organization may initiate the transfer process at the individual level, given the necessary conditions are satisfied but to make it the culture of an organization or a routine activity, the organization must provide supportive conditions. Table-3 summarizes necessary and supportive conditions as follows, 


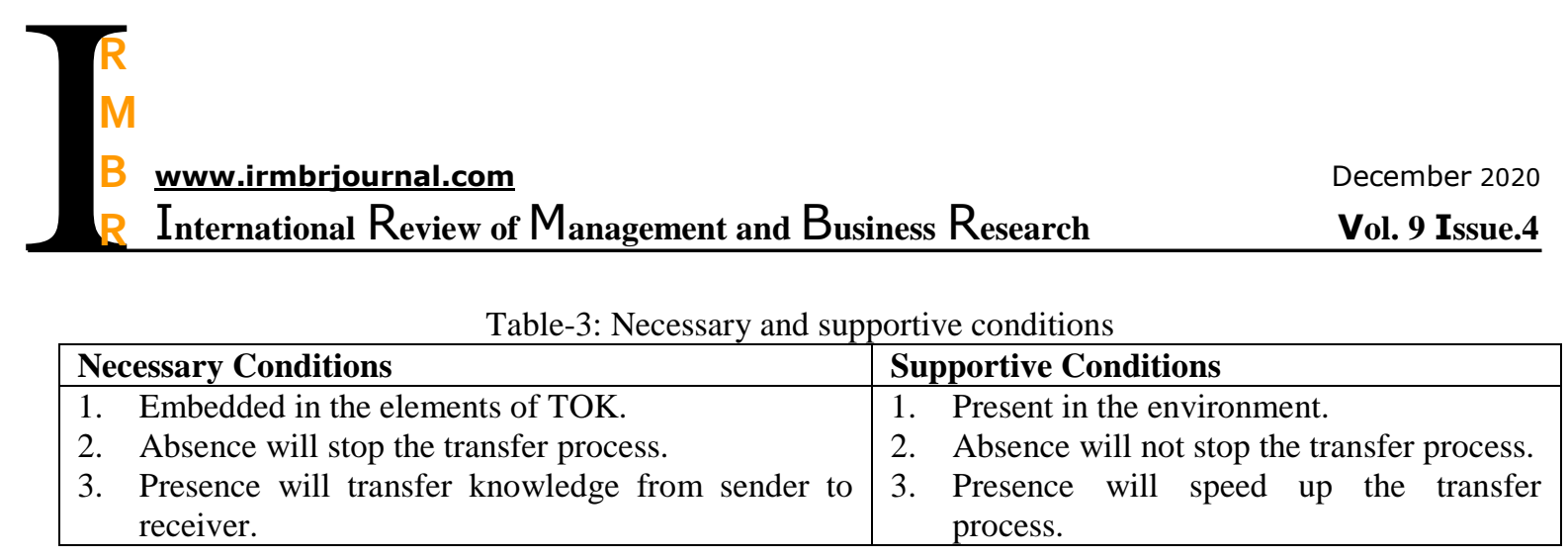

Figure No: 2

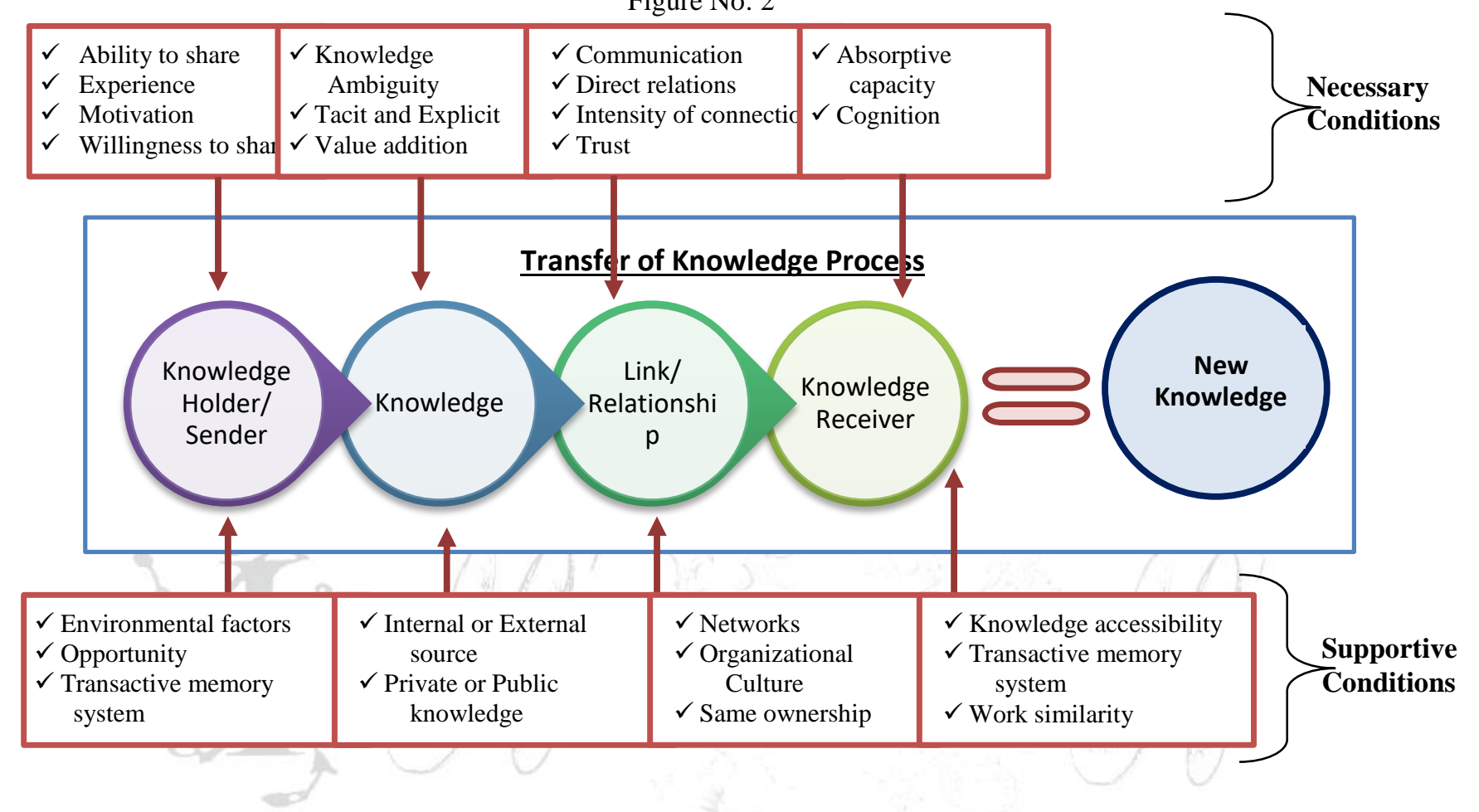

\section{The Way Forward}

The given framework is a conceptual understanding of how knowledge can be transferred from a knowledge holder to a knowledge receiver. It defines the elements of the transfer process and their required conditionality. This framework can assist decision-makers not only to focus on the elements of the transfer process and help develop their required conditionality but can also help them in locating bottlenecks of the transfer process. Furthermore, the framework will also assist the decision-makers/managers in identifying and providing the appropriate conditions for TOK. However, it is suggested for future research that each of these conditionality's is empirically tested.

\section{References}

Ahammad, M. F., Tarba, S. Y., Liu, Y., \& Glaister, K. W. (2016). Knowledge transfer and cross-border acquisition performance: The impact of cultural distance and employee retention. International business review, 25(1), 66-75.

Ahmad, M., Mushtaq, I., \& Umar, R. M. (2019). Knowledge Sharing and Affective Commitment: Mediating Role of Trust between Knowledge Sender and Receiver. Journal of Management and Research, 6(2), 1-17.

Al-Alawi, A. I. and Al-Marzooqi, N. Y. (2007). Organizational Culture and Knowledge Sharing: Critical Sucess Factors", Journal of Knowledge Management, Vol 11, No. 2, pp 22-42. 
Al-Jabri, H., \& Al-Busaidi, K. A. (2018). Inter-organizational knowledge transfer in Omani SMEs: influencing factors. VINE Journal of Information and Knowledge Management Systems.

Antonelli, C., \& Colombelli, A. (2018). External and internal knowledge in the knowledge generation function. In The Evolutionary Complexity of Endogenous Innovation. Edward Elgar Publishing.

Bhagat, R. S., Kedia, B. L., Haveston, P. D. and Triandis, H. C. (2002) "Cultural Varriations In The CrossBorder Transfer Of Organizational Knowledge: An Integrated Framework", Academy Of Management Review, Vol 27, No. 2, pp 204-221.

Bolisani, E., \& Bratianu, C. (2018). The emergence of knowledge management. In Emergent knowledge strategies (pp. 23-47). Springer, Cham.

Borgatti, S. P. and Cross, R. (2003). A Relational View Of Information Seeking And Learning In Social Networks, Management Science, Vol 49, No. 4, pp 432-445.

Bou-Llusar, J. C. and Segarra-Cipre's, M. (2006). Strategic Knowledge Transfer and Its Implications For Competitive Advantage: An Integrative Conceptual Framework, Journal of Knowledge Management, Vol 10, No. 4, pp 100-112.

Cabrera, E. (2003). Socio-Psychological Aspects of Knowledge Sharing In Organizations, Proceedings of the 7th Conference on International Human Resource Management, Limerick, 4-6 June.

Chase, R.L. (1997). The Knowledge-Based Organization: An International Survey, Journal of Knowledge Management, Vol 1, No. 1, pp 38-49.

Cialdini, R. B. (2001) Influence. Allyn \& Bacon, Needham Heights, MA.

Coff, R., Coff, D. and Eastvold, R. (2006). The Knowledge Leveraging Paradox: How To Achieve Scale Without Making Knowledge Imitable, Academy of Management Review, Vol 31, pp 1-13.

Cohen, W. M., and Levinthal, D. A. (1990). Absorptive Capacity: A New Perspective on Learning and Innovation, Administrative Science Quarterly, Vol 35, No.1, pp 28-152.

Darr E.D. and Kurtzberg T.R (2000). An Investigation of Partner Similarity Dimensions on Knowledge Transfer, Organizational Behavior Human Decision Process, Vol 82, No. 1, pp 28-44.

Das, T. K. and Teng, B. S. (2001). A Risk Perception Model of Alliance Structuring, Journal of International Management, Vol 7, pp 1-29.

Davenport, T.H., De Long, D.W. and Beers, M.C. (1998) "Successful Knowledge Management Projects", Sloan Management Review, Vol 39, No. 2, pp 43-57.

DeTienne, K.B. and Jackson, L.A. (2001). Knowledge management: understanding theory and developing strategy, Competitiveness Review, Vol 11, No. 1, pp 1-11.

Ellis, R., \& Roever, C. (2018). The measurement of implicit and explicit knowledge. The Language Learning Journal, 1-16.

Epple, D., L. Argote and K. Murphy. (1996). An empirical investigation of the microstructure of knowledge acquisition and transfer through learning by doing, Operational Research, Vol 44, pp 7786.

Grant, R. M. (1996). Prospering In Dynamically Competitive Environments: Organizational Capability as Knowledge Integration, Organization Science, Vol 7, pp 375-87.

Gruenfeld, D. H, Martorana, P. V., and Fan, E. T. (2000), "What Do Groups Learn From Their Worldliest Members? Direct and Indirect Influence in Dynamic Teams". Organizational Behavior and Human Decision Processes, Vol 82, pp 45-59.

Gupta, A., \& Govindarajan, V. (2000). Knowledge Flows within Multinational Corporations, Strategic Management Journal, Vol 21, No. 4, pp 473- 496.

Hadjimichael, D., \& Tsoukas, H. (2019). Toward a better understanding of tacit knowledge in organizations: Taking stock and moving forward. Academy of Management Annals, 13(2), 672-703.

Hansen, M. T. (1999). The Search-Transfer Problem: The Role of Weak Ties in Sharing Knowledge Across Organization Subunits, Administrative Science Quarterly, Vol 44, pp 82-111.

Ho, M. H. W., Ghauri, P. N., \& Kafouros, M. (2019). Knowledge acquisition in international strategic alliances: The role of knowledge ambiguity. Management International Review, 59(3), 439-463.

Ho, M. H.-W., \& Wang, F. (2015). Unpacking knowledge transfer and learning paradoxes in international strategic alliances: Contextual differences matter. International Business Review, 24(2), 287-297. 
Katz, R. and Allen, J. (1982). Investigating The Not Invented Here (NIH) Syndrome: A Look At The Performance, Tenure, And Communication Patterns Of 50 R\&D Project Groups, R\&D Management, Vol 121, pp 7-19.

Kogut, B. and Zander, U. (1992). Knowledge of the Firm, Combinative Capabilities and the Replication Of Technology, Organization Science, Vol 3, pp 383-97.

Krone, J.K., Jablin, F.M., and Putnam, L.L. (1987). Communication Theory and Organizational communication: Multiple perspectives. In: F.M., Jablin, L.L. Putnam; K.H., Roberts \& L.W. Porter (Eds). Handbook of Organizational Communication, Newbury Park: Sage Publications

Krylova, K. O., Vera, D., \& Crossan, M. (2016). Knowledge transfer in knowledge-intensive organizations: the crucial role of improvisation in transferring and protecting knowledge. Journal of Knowledge Management.

Lane, P. J. and Lubatkin, M. (1998). Relative Absorptive Capacity and Inter-organizational Learning, Strategic Management Journal, Vol 19, pp 461-777.

Lane, P. J., Salk, J. E. and Lyles, M. A. (2001). Absorptive Capacity, Learning, and Performance In International Joint Ventures, Strategic Management Journal, Vol 22, pp 1139-61.

Law, K. K. (2014). The problem with knowledge ambiguity. European Management Journal, 32(3), 444450.

Lee, H. \& Choi, B. (2003). Knowledge Management Enablers, Processes, and Organizational Performance: An Integrative View and Empirical Examination, Journal of Management Information Systems, Vol 20, No. 1, pp 179-228.

Liyanage, C., Elhag, T.,Ballal, T. and Li, Q. (2009). Knowledge Communication and Translation- A Knowledge Transfer Model. Journal of Knowledge Management, Vol 13, No. 3, pp 118-131.

Lyles, M. A. and Salk, J. E. (1996). Knowledge Acquisition from Foreign Parents in International Joint Ventures: An Empirical Examination of the Hungarian Context, Journal of International Business Studies, Vol 27, pp 877-904.

Martin-Rios, C., \& Erhardt, N. (2017). Small business activity and knowledge exchange in informal interfirm networks. International Small Business Journal, 35(3), 285-305.

Menon, T. and Pfeffer, J. (2003). Valuing Internal Versus External Knowledge, Management Science, Vol 49, No. 4, pp 497-513.

Minbaeva, D. B. and Michailova, S. (2004). Knowledge Transfer and Expatriation in Multinational Corporations: The Role of Disseminative Capacity, Employee Relations, Vol 26, No. 6, pp 663-679.

Montoya, R. D., \& Leazer, G. H. (2019). Public Knowledge, Private Ignorance, and an Analytic of Knowledge Organization. NASKO, 7(1), 174-182.

Mowery, D., Oxley, J. and Silverman, B. (1996). Strategic Alliances and Inter-Firm Knowledge Transfer, Strategic Management Journal, Vol 17, pp 77-91.

Narteh. B. (1998) "Knowledge Transfer in Developed-Developing Country Inter-Firm Collaborations: A Conceptual Framework", Journal of Knowledge Management, Vol 12, pp 78-98.

Palich, L. E. and Gomez-Mejia, L. R. (1999). A Theory of Global Strategy and Firm Efficiencies: Considering the Effects of Cultural Diversity, Journal of Management, Vol 25, pp 587-606.

Qin, C., Wang, Y., \& Ramburuth, P. (2017). The impact of knowledge transfer on MNC subsidiary performance: does cultural distance matter?. Knowledge Management Research \& Practice, 15(1), 7889.

Reed, R. and DeFilippi, R. J. (1990). Causal Ambiguity, Barriers to Imitation and Sustainable Competitive Advantage, Academy of Management Review, 15, pp 88-102.

Rhodes, J., Hung, R., Lok, P., Lien, B.Y. and Wu,C.M. (2008). Factors Influencing Organizational Knowledge Transfer: Implication for Corporate Performance. Journal of Knowledge Management, 12, pp 84-100.

Robenstein-Montano. B., Liebowitz. J., Buchwalter. J., McCaw. D., Newman.B. and Rebeck. K. (2001) "Smart vision: A knowledge management Methodology" Journal of Knowledge Management, 5 (4), 300-310. 
Rowley, T., Behrens, D. and Krackhardt, D. (2000). Redundant Governance Structures: An Analysis of Structural and Relational Embeddedness in the Steel Industries, Strategic Management Journal, Vol 21, pp 369-86.

Saiz, L., Miguel, D. P., \& Del Campo, M. Á. M. (2018). The knowledge absorptive capacity to improve the cooperation and innovation in the firm. Journal of Industrial Engineering and Management, 11(2), 290-307.

Seyedyousefi, N., Fard, S. M. H., \& Tohidi, F. (2016). The role of organizational culture in knowledge management. Mediterranean Journal of Social Sciences, 7(5), 412-412.

Singley. M. K. and Anderson. R. J. (1989). The Transfer of Cognitive Skill, Cambridge, Mass Harvard University press.

Sorenson, O. (2003). Interdependence and Adaptability: Organizational Learning and the Long-Term Effect of Integration, Management Science, Vol 49, No.4, pp 446-463.

Stonehouse, G.H. and Pemberton, J.D. (1999). Learning and Knowledge Management in the Intelligent Organization, Participation and Empowerment: An International Journal, Vol 7, No.5, pp 131-44.

Szulanski, G. (1996). Exploring Internal Stickiness: Impediments to the Transfer of Best Practice within the Firm, Strategic Management Journal, Vol 17(winter), pp 27-43.

Szulanski, G., Capetta, R. and Jensen, R. J. (2004) "When and How Trustworthiness Matters: Knowledge Transfer and the Moderating Effect of Causal Ambiguity", Organization Science, Vol 15, pp 600-13.

Torabi, F., Warnell, G., \& Stone, P. (2019). Recent advances in imitation learning from observation. arXiv preprint arXiv:1905.13566.

Tsang, E.W.K. (2002). Acquiring Knowledge by Foreign Partners from International Joint Ventures in a Transitional Economy: Learning-By- Doing and Learning Myopia, Strategic Management Journal, Vol 23, pp 835-54.

Uzzi, B., R. Lancaster. (2003). The Role of Relationships in Inter Firm Knowledge Transfer and Learning: The Case of Corporate Debt Markets, Management Science, Vol 49, No. 4, pp 383-399.

Wang, Y., Huang, Q., Davison, R. M., \& Yang, F. (2018). Effect of transactive memory systems on team performance mediated by knowledge transfer. International Journal of Information Management, 41, 65-79.

Webb, S. P. (2017). Knowledge management: Linchpin of change. Routledge.

Wegner, D. M. (1986). Transactive Memory: A Contemporary Analysis of the Group Mind. In: B. Mullen and G. R. Goethals, Ed. Theories of Group Behavior, New York: Springer-Verlag.

Wei, Y., \& Miraglia, S. (2017). Organizational culture and knowledge transfer in project-based organizations: Theoretical insights from a Chinese construction firm. International Journal of Project Management, 35(4), 571-585.

Winter, S. G., and Szulanski, G. (2001). Replication as Strategy, Organization Science, Vol 12, pp 730743. 